\title{
In Vitro Analysis of the Cytocompatibility of a Novel Porcine Aortic Patch for Vascular Reconstruction
}

\author{
SVEN PANTERMEHL ${ }^{1}$, SAID ALKILDANI ${ }^{2}$, ELISA MEYER ${ }^{1}$, IGNACIO STOWE ${ }^{3}$, \\ JENS PISSAREK ${ }^{4}$, PIA MOOSMANN ${ }^{4}$, OLE JUNG $^{1 *}$ and MIKE BARBECK ${ }^{2 *}$ \\ ${ }^{1}$ Clinic and Policlinic for Dermatology and Venereology, \\ University Medical Center Rostock, Rostock, Germany; \\ ${ }^{2}$ BerlinAnalytix GmbH, Berlin, Germany; \\ ${ }^{3}$ Helios Clinic Emil von Behring, Vascular Center Berlin Southwest, Berlin, Germany; \\ ${ }^{4}$ Biotrics Bioimplants AG, Berlin, Germany
}

\begin{abstract}
Background/Aim: Cardiovascular diseases are one of the most common causes of morbidity and mortality in the world. In the case of severe arteriosclerotic damage, surgical treatment is necessary. Although the use of autologous vessels is still considered to be the gold standard, sufficient autologous vessels for transplantation are lacking. Materials and Methods: In the present study, histological examination and in vitro cytotoxicity analysis according to DIN EN ISO 10993-5 were performed on a newly developed porcine vascular graft from a decellularized aorta. A conventional bovine graft was used as control. Results: The ex vivohistological analysis revealed the effectiveness of a new purification process on the microstructure and the removal of xenogeneic antigen-bearing structures in the new vessels. Furthermore, cell viability and cytotoxicity assays revealed full cytocompatibility. Conclusion: The novel graft shows no structural damage and gets completely decellularized by the purification process. Superior cytocompatibility, compared with the bovine-derived vascular graft, was demonstrated.
\end{abstract}

Cardiovascular diseases like cerebral, coronary and peripheral artery diseases are one of the most frequent causes of morbidity and mortality, especially in industrialized nations $(1,2)$. The luminal narrowing of the vessels and the

This article is freely accessible online.

*These Authors contributed equally to this study.

Correspondence to: Dr. Mike Barbeck, Ullsteinstrasse 108, 12109 Berlin, Germany. Tel: +49 17681022467, e-mail: mike.barbeck@berlinanalytix.com

Key Words: Cardiovascular, collagen, vascular graft, in vitro, cytocompatibility, aortic patch, decellularized vascular graft, porcine, bovine. resulting insufficient supply of the downstream organs and tissues with oxygen and nutrients, as well as the potential complete vascular occlusion or spontaneous vascular rupture, are preceded by frequent arteriosclerotic changes in the vessels $(3,4)$. The presence of a manifest cardiovascular disease can dramatically increase, e.g., both the risk of the emergence of a heart attack and a stroke (5). Depending on the exact location and extent of the occlusion, various therapy options are possible. In addition to conventional drug therapy, various surgical methods are common, especially for high-grade occlusions. This includes percutaneous transluminal angioplasty (PTA) or, for the coronary vessels, percutaneous coronary intervention (PCI), as well as thrombo-endarterectomy (TAE) with and without additional repair patch, but also direct vascular replacement by inserting an interposal or bypass surgery $(6,7)$.

Restoring blood flow through the installation of a bypass system is often the preferred method, particularly in the case of long occlusions. There are various options available to the surgeon when choosing the bypass material. In addition to autologous transplants from the patient's own vessels, this also includes homografts, processed xenografts, completely synthetic and biohybrid grafts. Autologous grafts are still considered the gold standard for interventional vascular replacement today, as they allow for the best clinical outcomes $(8,9)$. Depending on the location of the vascular stenosis, age, general health and comorbidities of the patient, different vessels can be used. In addition to the great saphenous vein and the saphenous vein, the internal thoracic artery as well as the ulnar artery and the radial artery or the right gastroepiploic artery are among the generally preferred transplants for the different indications in bypass surgery $(8,10)$.

As an endogenous material, autologous transplants come with the advantage of a naturally satisfactory immunological acceptance after implantation (11). In their original capacity as vessels, these transplants have good hemodynamic and 
hemocompatible properties, which are also associated with reduced thrombogenicity. Nevertheless, autologous vascular grafts also come with some limiting complications. In addition to further atherosclerotic changes in the bypasses, that can occur within the graft post transplantationem, this also includes platelet activation and thrombosis of the conduits as well as occluding intraluminal hyperplasia of the intima, particularly in the anastomotic areas of the transplants (12-14). Furthermore, pre-existing degenerative processes such as varicose degeneration or intramural calcifications, which can be already present in many of the patients who typically require bypass surgery, can render the vessels unusable for a transplant (15). In addition, the size of the vessels intended for transplantation sometimes does not match the required vessel size and is therefore also unsuitable.

In the late 1940s, alloplastic grafts made of synthetic materials such as polyester and polyethylene terephthalate (PET; Dacron ${ }^{\circledR}$ ) or expanded polytetrafluoroethylene $\left(\mathrm{ePTFE}^{\circledR}\right)$ were introduced to vascular surgery $(16,17)$. Even if autologous vessels are the most common transplant material, synthetic bypasses are an alternative that is still in use, in particular for the replacement of large-volume vessels like the aorta or superior or inferior vena cava or when autologous grafts are not available $(17,18)$. A great advantage of these alloplastic grafts is their "off the shelf" availability, even with different diameters and lengths, whereas the surgeon is largely dependent on the patient's anatomical conditions when using the body's own vessels. By additionally coating the inside of the graft with different glycosaminoglycans or proteins, like heparin, the patency rate can be significantly improved, so that these grafts are classified as a therapy option equivalent to autologous veins in selected indications $(17,19,20)$. At the same time, synthetic grafts in particular for the replacement of smalllumen vessels $(<6 \mathrm{~mm})$ have a higher risk of thrombotic occlusions or intimal hyperplasia due to bad graft compliance mismatch, which results in poor long-term opening rates (2124). Furthermore, synthetic vascular graft materials are still associated with a higher risk of infection in the graft area (21, 22). Additionally, complications can occur due to the expansion of the grafts over time, as well as due to the mostly inadequate tissue integration of the alloplastic vessels (15).

With xenogeneic vessels, a further alternative to vascular transplantation was created in parallel to synthetic materials. One of the biggest problems to solve was the immune reaction of the recipient to the foreign material of the xenogeneic transplant. This issue could be initially overcome by using proteolytic enzymes to remove the cellular donor material in combination with chemical tanning processes of the remaining collagen structure via formaldehyde or dialdehyde (25). The resulting decellularized extracellular matrix scaffolds are in use in various vascular surgery indications, today especially in shunt surgery (25-27). The low risk of infection in particular, is one of the biggest advantages of xenogeneic transplants, in addition to their almost unlimited "off the shelf" availability and various lengths available (28).

As already mentioned, every animal donor tissue must first undergo a special purification process before it is suitable for implantation in the human organism. The most important potential causes for a failure of the scaffolds after their transplantation are an increased proinflammatory immune defense reaction of the recipient, altered mechanical properties as well as inadequate or faulty cellular integration (29). For this reason, the manufacturing process has to address the removal of antigen-afflicted structures through a thorough decellularization process and withal, not to destroy the structural integrity of the remaining collagen framework. Various manufacturing protocols have been tried in the past with the aim of achieving this balance between purification and structure retention (30-32).

Aim of the study is a newly developed xenogeneic vascular graft material based on native collagen obtained from the aorta of pigs. The processing protocol on which the production of this graft is based has last been established for purification of dental collagen-based biomaterials. Therefore, as part of this study, it should be investigated whether the procedure is also suitable for the purification of xenogeneic vascular grafts. The aim of the present study was an initial histological assessment of the decellularized graft and to test the cytocompatibility of the newly developed graft material. Established in vitro procedures were used to analyze the cytocompatibility under the test conditions of DIN EN:ISO 10993-5 (33-35). As control, an already commercially available collagen-based vessel graft (XenoSure ${ }^{\circledR}$, LeMaitre Vascular, Vaughan, ON, Canada) was additionally brought in.

\section{Materials and Methods}

Manufacture of the new collagen-based vascular graft. The porcine aortas required for production were obtained from adult pigs after slaughter. The uppermost layer of the adventitia was carefully removed and the aortas prepared in this way were stored in $0.1 \mathrm{M}$ ethylenediaminetetraacetic acid (EDTA; Carl Roth, Karlsruhe, Germany) solution. The decellularization process required several chemical treatment steps, which are described hereafter. At first, the samples were cleaned in demineralized water for one hour and then incubated in sodium hypochlorite solution (0.5\%) (Bioanalytic $\mathrm{GmbH}$, Freiburg, Germany) for $10 \mathrm{~min}$. The samples were then incubated in TSP buffer (pH 7.4; PanReac AppliChem ITW Reagents, Darmstadt, Germany) for a further $60 \mathrm{~min}$. Afterwards, the aortas were treated with hydrogen peroxide (TH. Geyer, Renningen, Germany) for another hour. This step was followed by incubation in $0.02 \mathrm{M}$ phosphoric acid (PanReac AppliChem ITW Reagents, Darmstadt, Germany) for $19 \mathrm{~h}$. For the final step, the samples were incubated in TSP buffer $(\mathrm{pH}$ 7.4) for $3 \mathrm{~h}$. Decellularized samples were kept in a $0.1 \mathrm{M}$ EDTA and $3 \%$ sodium chloride (Carl Roth, Karlsruhe, Germany) at $4^{\circ} \mathrm{C}$. 
Histological analysis. An initial histological analysis was carried out to enable a primary assessment of the effects of the previously described decellularization process on the vascular grafts. Initially, samples of both the decellularized and untreated aortas as well as the control material were fixed in $4 \%$ formalin 48 hours at room temperature. The fixed samples were then dehydrated and treated with xylene for following paraffin embedding (Merck KGaA, Darmstadt, Germany).

Using a rotary microtome (SLEE, Mainz, Germany), 3-5 $\mu \mathrm{m}$ thick pieces were cut from the embedded samples. These pieces were dewaxed and stained with an H\&E staining kit (Clin-Tech, Guildford, UK) according to the manufacturer`s protocol. Paraffin sections of the XenoSure ${ }^{\circledR}$ vascular patch (LeMaitre Vascular) were made according to the same protocol. Histological analysis was then performed and microscopic images of the stained sections were taken with an AxioCam 305 color digital camera connected to a light microscope Axioscope 5 in combination with the ZEN Core software (all: Zeiss, Oberkochen, Germany).

\section{In vitro experiments.}

Cytocompatibility analysis: The cytocompatibility analysis was carried out in accordance with the requirements of DIN EN ISO 10993-5:2009/-12 2012. The individual steps in cell culture and sample treatment necessary for the test preparation as well as the assay protocols have already been described in detail in earlier publications and are therefore briefly summarized $(33,34)$. RM-A test samples [polyurethane film with $0.1 \%$ zinc diethyldithiocarbamate (ZDEC) (Hatano Research Institute, Food and Drug Safety Center, Japan)] were used as positive controls. Titanium Grade 4 platelets were chosen as negative controls. An already commercially available collagen-based vascular transplant (XenoSure ${ }^{\circledR}$, LeMaitre Vascular) served as reference material for the newly developed xenogeneic vessel graft. To produce the required extracts, both the samples and the positive and negative controls were embedded in extraction medium at $37^{\circ} \mathrm{C}, 5 \% \mathrm{CO}_{2}$ and $95 \%$ humidity for $72 \pm 2 \mathrm{~h}$. The produced extracts were then transferred to L-929 mouse fibroblasts, purchased from the European Collection of Cell Cultures, ECACC (Salisbury, UK) and incubated for further $24 \mathrm{~h}$ under standard cell culture conditions $\left(37^{\circ} \mathrm{C}, 5 \% \mathrm{CO} 2\right.$ and $95 \%$ humidity). An XTT cell viability assay (Roche Diagnostics, Mannheim, Germany) and a cytotoxicity LDH assay (BioVision, Milpitas, CA, USA) were carried out afterwards. Blank values were subtracted from all obtained values.

Live-dead staining. For Live-Dead staining, both samples and controls were seeded with L-929 fibroblasts. In accordance with the corresponding ISO protocol, $2.4 \times 10^{5}$ cells in $1 \mathrm{ml}$ cell medium were added into each well of a 12-well-plate (surface-area/medium ratio was $5.65 \mathrm{~cm}^{2} / \mathrm{ml}$ ). As for the cytocompatibility analysis, RM-A served as a positive control and titanium grade 4 platelets as a negative control. The assays were carried out after $24 \mathrm{~h}$ of incubation under cell culture conditions $\left(37^{\circ} \mathrm{C}, 5 \% \mathrm{CO}_{2}\right.$ and $95 \%$ humidity). After staining, the samples were examined under an inverted fluorescence microscope (Nikon ECLIPSE Ti-S/L100, Nikon GmbH, Düsseldorf, Germany) equipped with a filter for the simultaneous detection of red and green fluorescence. The pictures were taken under the use of $4 \times, 10 \times$, and $20 \times$ objective magnifications.

Statistics. Statistical analysis was carried out by applying ANOVA combined with a Tukey's multiple comparisons test using GraphPad
Prism 8.0 software (GraphPad Software Inc., La Jolla, CA, USA). Statistical differences were considered significant if the $p$-values were less than $0.05\left({ }^{*} p \leq 0.05\right)$. A statistically high significance was defined for $p$-values less than $0.01(* * p \leq 0.01)$ or less than $0.001(* * * p \leq 0.001)$. The data are presented as mean values \pm standard deviation.

\section{Results}

Histological analysis. The histological analysis revealed that the novel vessel graft material showed the tissue-specific three-layer structure of vessel walls, consisting of (a) tunica intima, (b) tunica media and (c) tunica adventitia that were clearly identifiable before and after the purification process (Figure 1). In the non-purified sample, in addition to the elastic and collagen fibres of the extracellular matrix, the cells of the donor tissue were clearly visible in all layers of the vessel wall (Figure 1B-D). In addition, the lumen of socalled vasa vasorum (V.V.) were observable within the tunica adventitia of the non-purified graft (Figure 1D).

Furthermore, the novel vessel graft was examined after decellularization according to the purification protocol (Figure 1E-G). It was seen that the elastic and collagen fibres of the graft have been preserved and their structural integrity has not been disturbed by the purification process. The fibres appeared in all layers of the vessel in the tissue-typical longitudinal orientation after decellularization. At the same time, no remaining cells were microscopically detected. Additionally, a distinction between the tunica intima and tunica media was complicated due to the lack of the intimatypical intraluminal endothelial cell layer even after purification (Figure 1E).

In addition, the XenoSure ${ }^{\circledR}$ vascular patch (LeMaitre Vascular) was examined histologically (Figure 2). In contrast to the newly developed vascular graft, there was no histological subdivision of the tissue into several physiologic layers for the patch, but a consistently uniform connective tissue structure (Figure 2A). The collagen fibres present in the tissue matrix did not run in a uniform longitudinal direction, but rather showed a non-uniform course, especially in the outer areas of the patch (Figure 2B). Furthermore, several remaining native cells were seen within the purified patch (Figure 2B and C).

Live-dead staining. Both transplants showed extensive green fluorescent cells, similar to the negative control (Figure 3). Living cells could be detected both on the surface of the samples (directly) and next to the materials (indirectly) (Figure 3). On the newly developed vessel graft, fewer fibroblasts seemed to have grown adherently than on the control graft XenoSure ${ }^{\circledR}$ (LeMaitre Vascular), indicating a potentially decreased adhesion of vital cells on the surface of the novel graft (Figure 3I-P). As expected, the RM-A positive control showed almost exclusively red fluorescent 

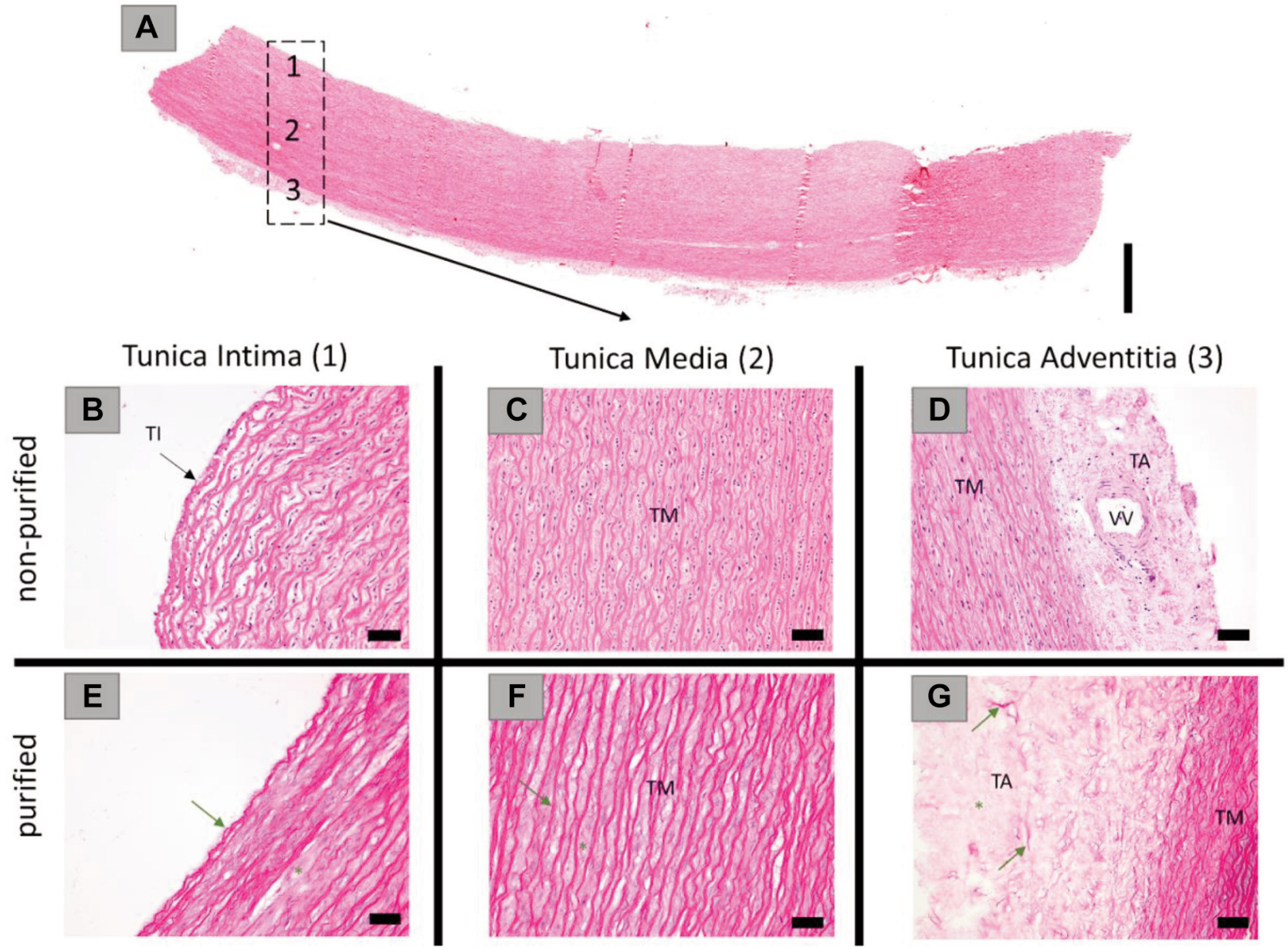

Figure 1. Representative microscopic images of the novel vascular graft, won from porcine aorta. (A) Overview of the vascular graft material showing its three-layer structure (HE-staining, "total scan", 100x magnification, scalebar=1 mm). (B-G): Detailed representation of the tunica intima, tunica media, and tunica adventitia of the non-purified donor tissue $(B-D)$ and the purified graft material $(E-G)$. Microstructure including loose collagen (green asterisk) and elastic fibers (green arrows) is visible. (HE-stainings, 20x magnifications, scalebars=50 $\mu \mathrm{m}$ ). TI: Tunica intima; TM: tunica media; TA: tunica adventitia; VV: vasa vasorum.

and rounded dead cells and only very few living fibroblasts (Figure 3A-D).

Cytocompatibility assays. According to DIN EN ISO 10993, the nontoxic range for biomaterials necessary for the assessment of cytocompatibility was defined for values $\geq 70 \%$ compared to the blind control for XTT assays and for values $\leq 130 \%$ compared to the blind control for LDH assays (34, 36 ). In the assays carried out, the values in the group of the novel vascular graft were within the defined non-toxic ranges (Figure 4). Therefore, an adequate cytocompatibility was assumed. In the XTT assay, the newly developed graft differed significantly $(* * * p<0.001)$ from the reference materials and showed significantly $(p \leq 0.001)$ higher cell viability than that measured in the group of the XenoSure ${ }^{\circledR}$ graft (LeMaitre Vascular), which did not reach the required non-toxic area in this assay (Figure 4A). In the LDH test, the values in the groups of both grafts, as well as in the group of the blank sample and the negative control, were within the non-toxic range. At the same time, no significant differences were shown for the values of the grafts among each other or in comparison to the titanium grade 4 negative control group (Figure 4B).

\section{Discussion}

Up to date, autografts are the gold standard for the interventional treatment of cardiovascular diseases but are nevertheless often limited in use due to pre-existing degenerative alterations or mismatches between the size of the available vessels in the patient and the size necessary for the transplantation. Therefore, the use of autogenous grafts is not always available, thus creating a need for suitable 

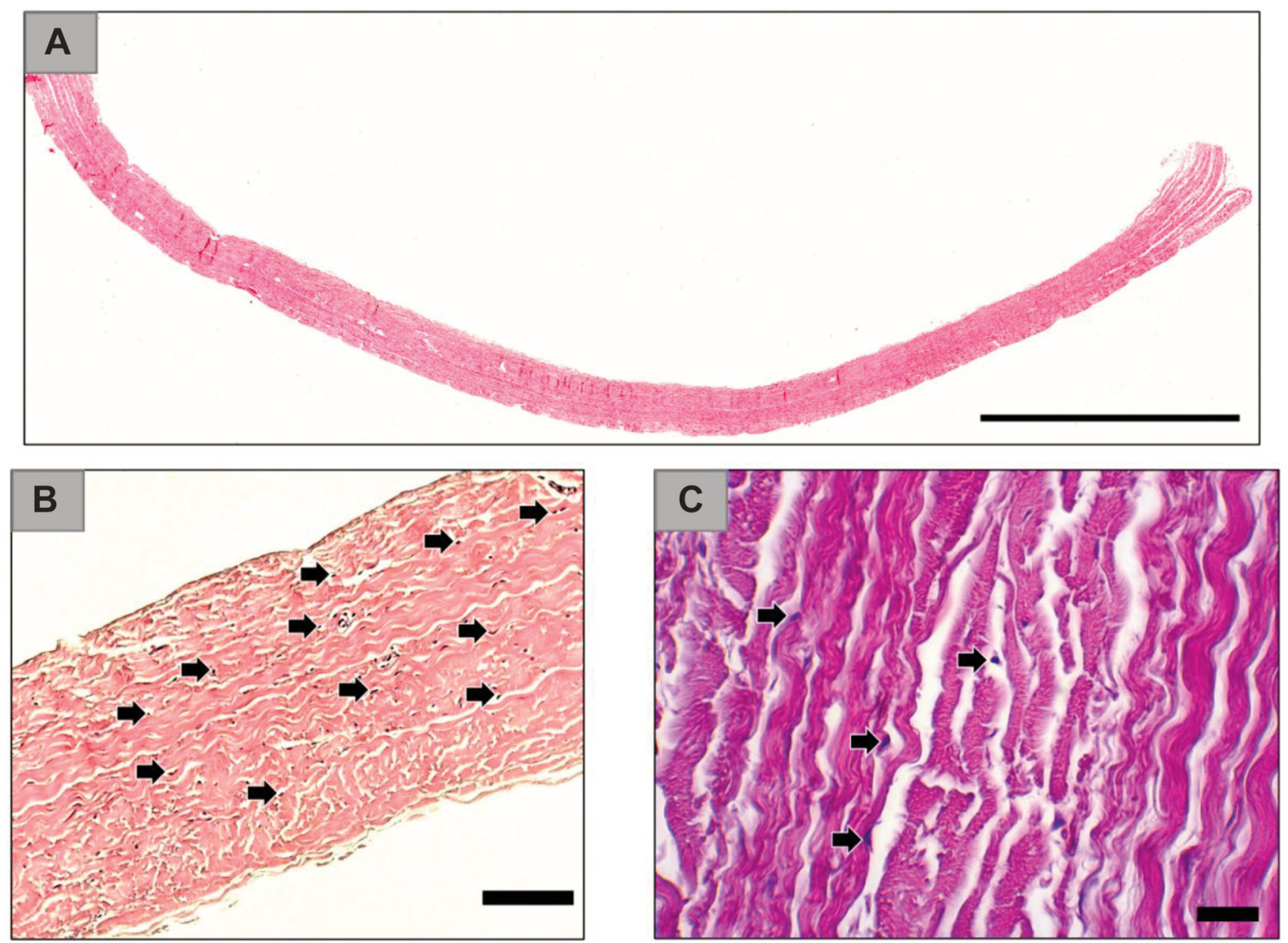

Figure 2. Representative microscopic images of the XenoSure ${ }^{\circledR}$ vascular patch. (A) Overview of the vascular graft material (HE-staining, "total scan", 100x magnification, scalebar $=2 \mathrm{~mm}) .(B)$ and $(C)$ : Detailed representation of the ultrastructure of the graft material (HE-staining, B: 20x magnification, scalebar $=100 \mu \mathrm{m} ; C: 40 \times$ magnification, scalebar $=50 \mu \mathrm{m})$. Black arrows $=$ cells.

alternatives. Alloplastic grafts, such as those made from PET or PTFE may come with an "off the shelf" availability and with variable sizes and diameters, but are also associated with higher infection risks and graft compliance mismatches, along with resulting thrombotic occlusions or intimal hyperplasia (21-24). Furthermore, as they are made from synthetic materials, they lack bioactivity and are therefore limited in their ability of sufficient tissue integration, associated with possible long-term complications. A promising combination of an "off the shelf" availability in different sizes, low infection risks, and good tissue integration due to given bioactivity lies within the use of xenogeneic grafts. These conduits have to undergo complex purification processes in order to remove remaining xenogeneic antigens, as they can trigger inflammatory immune responses and may result into a transplantation failure (30-32). Beside the removal of potential antigen bearing structures within the graft, the ideal purification process should not have a negative effect on the overall biocompatibility of the material nor on the basic structure, as it is essential for a sufficient tissue integration and functionality of the graft (37).

In this context, the aim of the present study was to examine the ultrastructure and the cytocompatibility of a newly developed xenogeneic vascular graft originating from the porcine aorta compared with a commercially available bovine pericardium-based collagen patch (XenoSure ${ }^{\circledR}$, LeMaitre Vascular). Initially, histological sections were made to examine the quality of the purification of both medical devices. Afterwards, cytocompatibility analysis consisting of indirect XTT - and LDH - assays as well as direct testing using Live-Dead staining were carried out.

Through the histological analysis, both the structural differences of the investigated grafts and the different effects 


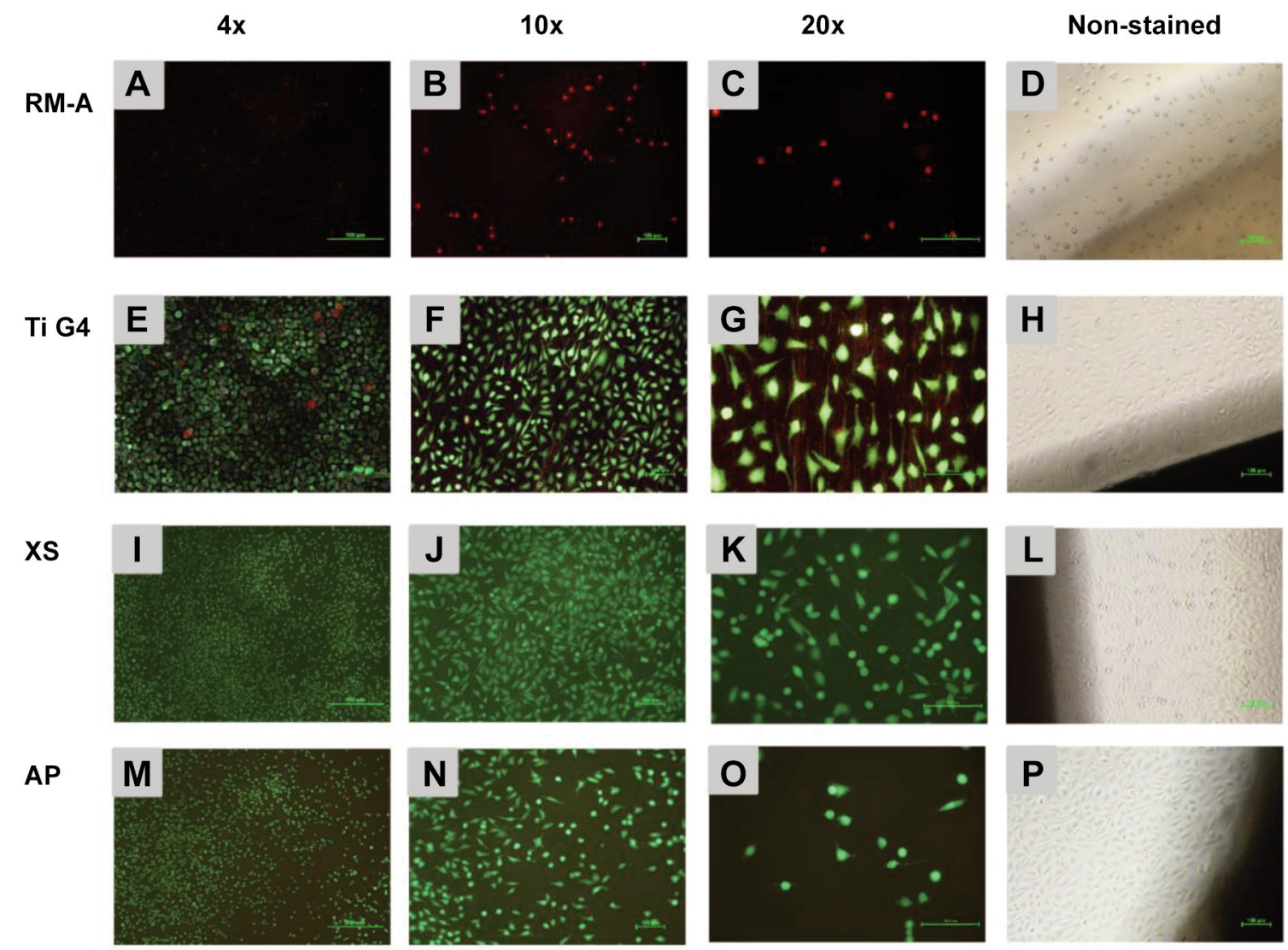

Figure 3. Live-Dead staining $(4 \times, 10 \times$ and $20 \times$ magnification) and microscopic images (right column, 10x magnification) of L-929 fibroblasts on, $R M-A$ (toxic) positive control (A-D), titanium grade 4 negative control $(E-H)$, the XenoSure ${ }^{\circledR}$ Graft $(X S)(I-L)$ and the novel aortic patch $(A P)(M-$ $P$ ) (scale bars: $4 \times$ magnification $=500 \mu \mathrm{m}, 10 \times$ and $20 \times$ magnification $=100 \mu \mathrm{m}$ ).

of the respective decellularization processes could be assessed. The novel vascular graft was produced from a porcine aorta and therefore, has its typical trilaminar structure, consisting of a tunica intima, tunica media and tunica adventitia with different distribution of elastic and collagen fibers (38-40). The histological images made before and after the purification of the material indicate a complete decellularization of the transplant with preservation of the native connective tissue and its trilaminar structure (Figure 1). However, a microscopic distinction between the tunica intima and the tunica media was no longer possible after the purification, as the monolayer of endothelial cells, typical for the tunica intima and its only microscopic distinguishable characteristic, was completely removed from the remaining ECM. The bovine pericardium of the XenoSure ${ }^{\circledR}$ vascular patch (LeMaitre Vascular), on the other hand, has an almost uniform tissue structure with overlapping collagen bundles, showing a wavy appearance and directed in various directions. The overall structure of the patch is in general homogenous and without any multi-layered differentiations. In addition, the histological analysis of the XenoSure ${ }^{\circledR}$ patch revealed several remaining cells and cell remnants, even after the purification of the native material (Figure 2).

Based on these structural differences, it is assumable that the two investigated grafts show distinct patterns of tissue integration and therefore, in their long-term outcome after transplantation. In fact, various tissue integration processes were observed in an initial in vivo study of the two biomaterials (41).

The novel porcine aortic patch showed a distinctly different integration pattern of the XenoSure ${ }^{\circledR}$ patch. The novel aortic graft induced only a mildly and physiological inflammatory tissue reaction and can therefore be assumed as biocompatible. The tunica adventitia of the aortic patch exhibited a rapid cell-mediated degradation were macrophages and multinucleated giant cells (MNGCs) were seen. During the analysis of the tunica media, a primary invasion with mononuclear cells, followed by a replacement with more complex tissue, based on mainly macrophages, fibroblasts, and blood vessels could be observed. This indicates that cellular migration into this patch is sufficient. Both into the tunica media and especially within the region 
A

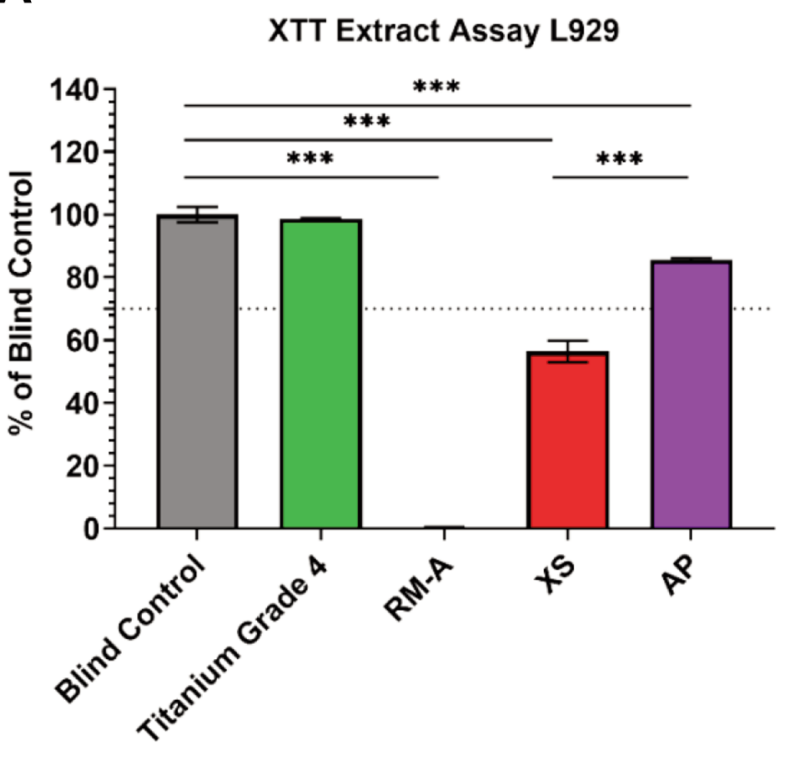

B

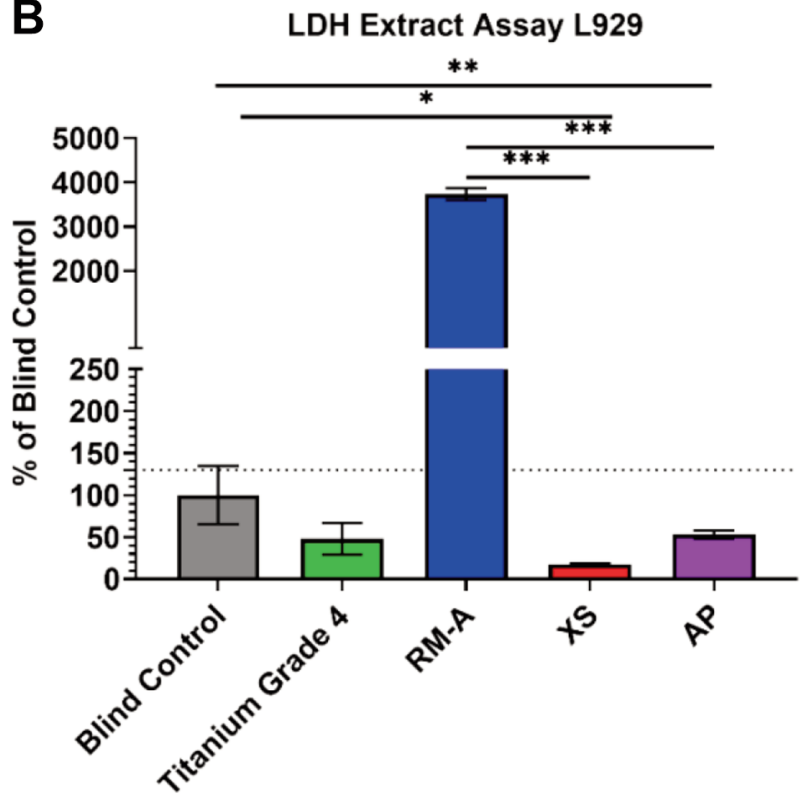

Figure 4. Photometric levels of (A) Sodium 3,3'-[1(phenylamino)carbonyl]-3,4-tetrazolium]-3is(4-methoxy-6-nitro) benzene sulfonic acid hydrate $(X T T)$-assay for cell viability and $(B)$ lactate dehydrogenase (LDH)-assay for cytotoxicity analysis. Both assays were carried out under use of L929 fibroblasts. Obtained values are normalized against blind control. Mean values and standard deviation are represented. Dotted lines indicate thresholds that should not be exceeded $(L D H)$ or undershot $(X T T)$. Significant differences were marked accordingly $(* p \leq 0.05, * * p \leq 0.01, * * p \leq 0.001)$. (XS: XenoSure ${ }^{\circledR}$ Graft; AP: Aortic Patch).

of the former tunica adventitia, mimicking the vasa vasorum in this layer of native vessels. Thus, leading to a promising long-term tissue integration that supplies the graft with nutrients and biomolecules. The XenoSure ${ }^{\circledR}$ control graft, on the other hand, showed a homogenous tissue reaction at both sides of its implantation bed, complaint with its monolayered overall structure. The foreign body reaction was similar to the aortic patch in terms of cell types and population; hence, also deemed biocompatible. However, and in contrast to the novel porcine-based graft, cellular remigration and vascularization were mainly shown in the superficial layers of the XenoSure ${ }^{\circledR}$ patch. The centre of the biomaterial stayed mostly cell free, thus indicating a significantly delayed or completely absent remigration of this areas. These observations were reported before in the context of pericardium-based biomaterials $(33,35)$. However, the mainly superficial cell invasion of the biomaterial in addition to the insufficient and slow revascularization is a well-known drawback of pericardium-based biomaterials, as it inhibits a fast tissue integration and might be a considerable factor for occurring complications after implantation including graft infections $(33,35)$.

The persistence of the extracellular matrix is necessary to create a scaffold for colonization by the patient's own cells in vivo after implantation or in vitro via tissue engineering $(42,43)$. In this context, it is notable that the molecules, making up the ECM, are similar across species lines and do not lead to an exaggerated immune response (44).

The investigated novel vascular graft was completely decellularized after the purification process (Figure 1E-G). It can be assumed, that this cell-free biomaterial does not induce an exaggerated immune-mediated inflammatory response after implantation. An initial approval of this assumption was reached within the aforementioned in vivo investigation with a demonstrated mild inflammatory tissue response and no immune-modulated rejection of the graft (41). In the case of the XenoSure ${ }^{\circledR}$ patch, on the other hand, several remaining cells of the bovine donor could be identified within the material (Figure 2B-C). Therefore, an immune-mediated rejection of the graft after implantation could be expected and even though it was not reported in vivo and clinically, a related reaction can still happen as these studies were not conducted for prolonged timepoints. Moreover, even if the cellular remnants do not induce an immune reaction, risk of bovine disease transmission (e.g., bovine spongiform encephalopathy) is of concern.

However, these aforementioned observations lead to some interesting questions, e.g., whether every cellular remnant is responsible for a distinct foreign body reaction, which antigen-bearing epitopes may be especially detected and how the applied decellularization process affects the immunogenicity of the cell residuals. Depending on whether 
enzymatic, physical or chemical purification protocols and which substances are used, the individual processes have different effects on the decellularization as well as on the mechanical and structural properties of the material $(42,43$, 45). In this context, modern decellularization protocols are not only focusing on the removal of residual donor cells, but on the purification of DNA remnants and especially Galactose- $\alpha$-1,3-galactose ( $\alpha$-Gal) epitopes. The latter is stated to be mainly responsible for hyperacute rejections especially in xenotransplantation and is expressed by most species, with exceptions of humans and some primates (42, 46). Thereby, every purification method comes with its own benefits and drawbacks. Chemical purification with sodium dodecyl sulphate (SDS), e.g., has a sufficient cell removal efficiency, but is inconclusive in terms of DNA purification $(42,46)$. Physical methods like freezing of the materials are effectively disrupting cell membranes, allowing a subsequently removal of the cellular contents by multiple washing or rinsing steps. On the other hand, these methods may be inefficient in terms of the purification of dense tissues, as the subsequent washing solution may fail to reach cellular components within deeper layers of the material (42). Enzymatic approaches like the use of DNAse may be very efficient in the elimination of DNA debris but need additional solutions to disrupt intact cell membranes and may be difficult to wash off the tissues afterwards (42). Therefore, the search for a sufficient and most effective purification process is still ongoing, as even the exact determination of all exaggerated immune response triggering epitopes and proteins stands still at its beginning, as identifying them is complex and still not fully understood (47). With the observed complete removal of cell residuals ex vivo and the precedent in vivo investigations, demonstrating mild immunogenic tissue reactions within the first 4 months post implantationem, the purification protocol applied on the novel vascular graft seems to be an effective approach for creating an immunological inert biomaterial. Nevertheless, further efforts should focus on long-term investigations as well as on an effective identification of potential remaining antigenic structures, capable of triggering an immunogenic mediated rejection of the biomaterial.

In the XTT and the LDH assay, the values of the novel porcine patch showed a clear cytocompatibility of the material. Thereby, the graft differed significantly from the blank sample in both assays. Furthermore, the new developed graft differed highly significantly from the XenoSure ${ }^{\circledR}$ patch (LeMaitre Vascular), which could not reach the tolerance range of this assay (XTT) as defined for cytocompatibility.

In Live-Dead staining, almost exclusively vital and adherent cells could be displayed for both materials, indicating a good cell survival and adhesion of the fibroblasts to the material surfaces. Furthermore, more fibroblasts adhered to the bovine pericardial patch than to the novel porcine graft. However, no significant number of dead, non-adherent cells could be detected on either of the two materials. The clearly shown high cell viability in the staining confirms the result of the indirect cytocompatibility assays. Therefore, a sufficient cytocompatibility of the novel graft after purification can be assumed. Thereby, the decellularization process removed the antigenic material of the donor animal from the remaining connective tissue framework of the aorta, without changing the structure, quality or composition of the material to such an extent that it had a negative effect on its cytocompatibility. Therefore, it could be expected that the process used in this study comes with at least the same quality as similar purification processes in terms of its influence on the cytocompatibility of decellularized xenogeneic vascular grafts, such as enzymatic treatment with Trypsin or mechanical decellularization via freeze-thaw of the material (48-50).

While the values for the XTT-assay of the newly developed transplant were clearly above the necessary threshold for cytocompatibility, the XenoSure ${ }^{\circledR}$ Patch (LeMaitre Vascular), already commercially available and used in vascular surgery, did not reach the required limit. A possible explanation for this result could be the manufacturing process and storage of this material. In order to improve the degradation rate and the mechanical properties of the collagen structure in the patch, it was subjected to chemical cross-linking using glutaraldehyde (GA) in the manufacturing process (51). Glutaraldehyde has been a widely used cross-linker since the 1980 s, especially for the production of medical-grade biomaterials (52). However, it should be noted that GA crosslinked collagen materials may come with a poorer biocompatibility, lower cell viability and adhesion than collagen-based materials produced using no or other crosslinking procedures (53-58). Furthermore, the patch is also supplied in liquid glutaraldehyde and has to be rinsed repeatedly before implantation. It is possible that the XenoSure $^{\circledR}$ (LeMaitre Vascular) samples analysed in the XTT assay could have been negatively influenced by the GA residues, even after rinsing. However, no remarkable negative effects on the cell viability were measured in the LDH assay or the Live-Dead staining.

The XenoSure ${ }^{\circledR}$ patch is a commercially and clinical established xenogeneic biomaterial with several cardiovascular indications. So far, no remarkable negative or cytotoxic effects are documented for its application. The mild inflammatory reactions post implantationem, as observed in the aforementioned in vivo study including the patch, seem to underline its sufficient biocompatibility (41). However, neither these in vivo investigations nor the current available clinical data to the material are suitable for sufficient long-term statements to the compatibility and degradation behaviour of the patch. Therefore, as with the 
novel porcine graft, further investigations and long-time studies are needed to obtain comprehensive information for both biomaterials.

The present study marks the beginning of extensive further investigations and continuous improvements of the developed vascular graft. It was possible to examine and confirm the cytotoxic safety and functionality as well as the ECM-maintaining properties of the new purification process on a decellularized porcine aorta. Nevertheless, beside the need of the aforementioned long-term in vivo as well as clinical analysis of the graft, several other interesting further questions should be in the focus of future investigations.

The blood-medical device dynamic interface in cardiovascular medicine has great influence on the service life of the implanted device; and hence, on the patient's safety (59). In vascular surgery, a direct interface between the implant and the blood can cause implant/organ damage, as well as intimal hyperplasia and thrombosis (60). A colonization of endothelial cells on the surface of the cardiovascular biomaterial can shield the implant, providing a remodelling potential. An endothelial cell layer acts as an interface between the blood flow and the surrounding tissue and has a significant regulatory influence on vasodilation and constriction, thrombus formation, and fibrinolysis as well as inhibition and stimulation of the vascular muscle cells (61$63)$. Furthermore, the integration of smooth muscle cells within the implanted conduits is of crucial importance for an adequate contraction and dilatation of the tissue (64). Although decellularized xenogeneic conduits have a higher potency for endothelialisation than alloplastic grafts, not all studies reported adequate endothelialisation as it heavily depends on the purification processes of the decellularized grafts and the preservation of their ECM adhesion components, that are important for the settlement of endothelial cells (59). Endothelialisation can be investigated in vitro and in vivo through different methods, including histochemical and immunohistochemical analyses of the endothelium (59). Further relative investigation of this novel aortic patch should be performed. If the hemocompatibility is deemed not sufficient, surface functionalization or cellular seeding prior to implantation can increase the potency of endothelialisation (65).

Depending on whether enzymatic, physical, or chemical purification protocols and which substances are used, the individual processes have different effects on the decellularization as well as on the mechanical and structural properties of the material $(42,43,45)$. In this context, three of the primarily considered components of the remaining tissue are collagen, elastin, and glycosaminoglycans (GAGs). Collagen is elemental to provide mechanical strength and structure stability (66). Elastin, on the other hand, plays an important role for extensibility and recoil of the tissue. These are properties with a certain importance for the functionality of pericardial or vascular tissues $(67,68)$. GAGs are, as part of the soluble protein fraction of the ECM, especially involved into the viscoelastic behaviour and hydration of several tissues (69). Histologically, both the collagen and the elastin fibres appear sustained within the materials, thus indicating a gentle purification process and therefore a sufficient recellularization capacity. However, Gratzer et al. stated in a previous study that the absence of collagen and GAGs in the ECM affects cell-integrin binding sites, making collagen more vulnerable for degradation (37). Thus, it can be crucial for the recellularization and endothelialisation of the vascular graft. Further analysis of the GAGs preservation should be carried out. Additionally, PCR analyses can provide further insights on the DNA content of the purified patches to avoid the transmission of disease and/or implant rejection.

Furthermore, a direct clinical comparison of the novel graft with other xenogeneic transplants as well as with synthetic and autologous conduits should be sought in terms of long-term patency, mechanical properties, and the risk of infection, in order to prove the potential equality or superiority of the newly developed porcine graft.

In order to be able to satisfactorily cover the need for transplants of different lumens, the application of the purification process should be extended to different xenogeneic vessels. Especially for grafts with lumina $>6$ $\mathrm{mm}$, there are little to no sufficient alternatives that can match autologous vascular grafts $(70,71)$. Synthetic transplants of this size are often associated with an increased risk of failure, as satisfactory reendothelialization is still difficult and inadequate, which leads to an increased tendency to thrombosis and inflammation-related intraluminal hyperplasia $(15,71,72)$. Thus, the purification of a naturally occurring xenogeneic small-lumen vessel and subsequent targeted recellularization in vitro appears to be a promising approach, that is already being tested with various manufacturing processes $(30,73,74)$.

Consequently, the primary goal of the following investigations will be to exploit the full potential of the novel porcine vascular graft.

\section{Conflicts of Interest}

The Authors declare no conflicts of interest in relation to this study.

\section{Authors' Contributions}

Conceptualization: I.S. J.P., O.J., M.B.; methodology: O.J., M.B.; software: S.P.; validation: S.P., S.A., P.M., O.J., M.B.; formal analysis: S.P., S.Al., M.B.; investigation: I.S., O.J., M.B.; resources: O.J., M.B.; data curation: S.P., S.A., E.M., M.B.; writing-original draft preparation: S.P., S.A.; writing-review and editing: O.J., M.B.; visualization: S.P., S.A.; supervision: M.B.; project administration: J.P., M.B. All Authors have read and agreed to the published version of the manuscript. 


\section{References}

1 Roth GA, Johnson C, Abajobir A, Abd-Allah F, Abera SF, Abyu G, Ahmed M, Aksut B, Alam T, Alam K, Alla F, Alvis-Guzman N, Amrock S, Ansari H, Ärnlöv J, Asayesh H, Atey TM, AvilaBurgos L, Awasthi A, Banerjee A, Barac A, Bärnighausen T, Barregard L, Bedi N, Belay Ketema E, Bennett D, Berhe G, Bhutta Z, Bitew S, Carapetis J, Carrero JJ, Malta DC, Castañeda-Orjuela CA, Castillo-Rivas J, Catalá-López F, Choi JY, Christensen H, Cirillo M, Cooper L Jr, Criqui M, Cundiff D, Damasceno A, Dandona L, Dandona R, Davletov K, Dharmaratne S, Dorairaj P, Dubey M, Ehrenkranz R, El Sayed Zaki M, Faraon EJA, Esteghamati A, Farid T, Farvid M, Feigin V, Ding EL, Fowkes G, Gebrehiwot T, Gillum R, Gold A, Gona P, Gupta R, Habtewold TD, Hafezi-Nejad N, Hailu T, Hailu GB, Hankey G, Hassen HY, Abate KH, Havmoeller R, Hay SI, Horino M, Hotez PJ, Jacobsen K, James S, Javanbakht M, Jeemon P, John D, Jonas J, Kalkonde Y, Karimkhani C, Kasaeian A, Khader Y, Khan A, Khang YH, Khera S, Khoja AT, Khubchandani J, Kim D, Kolte D, Kosen S, Krohn KJ, Kumar GA, Kwan GF, Lal DK, Larsson A, Linn S, Lopez A, Lotufo PA, El Razek HMA, Malekzadeh R, Mazidi M, Meier T, Meles KG, Mensah G, Meretoja A, Mezgebe H, Miller T, Mirrakhimov E, Mohammed S, Moran AE, Musa KI, Narula J, Neal B, Ngalesoni F, Nguyen G, Obermeyer CM, Owolabi M, Patton G, Pedro J, Qato D, Qorbani M, Rahimi K, Rai RK, Rawaf S, Ribeiro A, Safiri S, Salomon JA, Santos I, Santric Milicevic M, Sartorius B, Schutte A, Sepanlou S, Shaikh MA, Shin MJ, Shishehbor M, Shore H, Silva DAS, Sobngwi E, Stranges S, Swaminathan S, Tabarés-Seisdedos R, Tadele Atnafu N, Tesfay F, Thakur JS, Thrift A, Topor-Madry R, Truelsen T, Tyrovolas S, Ukwaja KN, Uthman O, Vasankari T, Vlassov V, Vollset SE, Wakayo T, Watkins D, Weintraub R, Werdecker A, Westerman R, Wiysonge CS, Wolfe C, Workicho A, Xu G, Yano Y, Yip P, Yonemoto N, Younis M, Yu C, Vos T, Naghavi $M$ and Murray C: Global, regional, and national burden of cardiovascular diseases for 10 causes, 1990 to 2015. J Am Coll Cardiol 70(1): 1-25, 2017. PMID: 28527533. DOI: 10.1016/j.jacc.2017.04.052

2 Virani SS, Alonso A, Benjamin EJ, Bittencourt MS, Callaway CW, Carson AP, Chamberlain AM, Chang AR, Cheng S, Delling FN, Djousse L, Elkind MSV, Ferguson JF, Fornage M, Khan SS, Kissela BM, Knutson KL, Kwan TW, Lackland DT, Lewis TT, Lichtman JH, Longenecker CT, Loop MS, Lutsey PL, Martin SS, Matsushita K, Moran AE, Mussolino ME, Perak AM, Rosamond WD, Roth GA, Sampson UKA, Satou GM, Schroeder EB, Shah SH, Shay CM, Spartano NL, Stokes A, Tirschwell DL, VanWagner LB, Tsao CW and American Heart Association Council on Epidemiology and Prevention Statistics Committee and Stroke Statistics Subcommittee: Heart disease and stroke statistics-2020 update: A report from the American Heart Association. Circulation 141(9): e139-e596, 2020. PMID: 31992061. DOI: 10.1161/CIR.0000000000000757

3 Copes F, Pien N, Van Vlierberghe S, Boccafoschi $F$ and Mantovani D: Collagen-based tissue engineering strategies for vascular medicine. Front Bioeng Biotechnol 7: 166, 2019. PMID: 31355194. DOI: 10.3389/fbioe.2019.00166

4 Zhuang Y, Zhang C, Cheng M, Huang J, Liu Q, Yuan G, Lin K and $\mathrm{Yu} \mathrm{H}$ : Challenges and strategies for in situ endothelialization and long-term lumen patency of vascular grafts. Bioact Mater
6(6): 1791-1809, 2020. PMID: 33336112. DOI: 10.1016/ j.bioactmat.2020.11.028

5 Gerhard-Herman MD, Gornik HL, Barrett C, Barshes NR, Corriere MA, Drachman DE, Fleisher LA, Fowkes FG, Hamburg NM, Kinlay S, Lookstein R, Misra S, Mureebe L, Olin JW, Patel RA, Regensteiner JG, Schanzer A, Shishehbor MH, Stewart KJ, Treat-Jacobson D and Walsh ME: 2016 AHA/ACC guideline on the management of patients with lower extremity peripheral artery disease: Executive summary: A report of the American College of Cardiology/American Heart Association Task Force on clinical practice guidelines. Circulation 135(12): e686-e725, 2017. PMID: 27840332. DOI: 10.1161/CIR. 0000000000000470

6 Glazier JJ, Ramos-Parra B and Kaki A: Therapeutic options for left main, left main equivalent, and three-vessel disease. Int $\mathrm{J}$ Angiol 30(1): 76-82, 2021. PMID: 34025098. DOI: 10.1055/s0041-1723977

7 Mares A and Mukherjee D: Management of chronic total occlusion of coronary artery. Int J Angiol 30(1): 48-52, 2021. PMID: 34025095. DOI: $10.1055 / \mathrm{s}-0040-1721478$

8 Martínez-González B, Reyes-Hernández CG, Quiroga-Garza A, Rodríguez-Rodríguez VE, Esparza-Hernández CN, ElizondoOmaña RE and Guzmán-López S: Conduits used in coronary artery bypass grafting: a review of morphological studies. Ann Thorac Cardiovasc Surg 23(2): 55-65, 2017. PMID: 28202895. DOI: $10.5761 /$ atcs.ra.16-00178

9 Zhang Q, Bosch-Rué È, Pérez RA and Truskey GA: Biofabrication of tissue engineering vascular systems. APL Bioeng 5(2): 021507, 2021. PMID: 33981941. DOI: 10.1063/ 5.0039628

10 Jannati M, Navaei MR and Ronizi LG: A comparative review of the outcomes of using arterial versus venous conduits in coronary artery bypass graft (CABG). J Family Med Prim Care 8(9): 2768-2773, 2019. PMID: 31681641. DOI: 10.4103/ jfmpc.jfmpc_367_19

11 Florek HJ: [Peripheral arterial reconstruction]. Chirurg 72(6): 747-54; quiz 754-5, 2001. PMID: 11469100. DOI: 10.1007/ s001040170135

12 Valdes PJ, Dorosh J, Lin JC and Diaz MA: Vein Graft Stenosis. 2021. PMID: 29763122.

13 Zhao Q, Zhu Y, Xu Z, Cheng Z, Mei J, Chen X and Wang X: Effect of ticagrelor plus aspirin, ticagrelor alone, or aspirin alone on saphenous vein graft patency 1 year after coronary artery bypass grafting: a randomized clinical trial. JAMA 319(16): 1677-1686, 2018. PMID: 29710164. DOI: 10.1001/jama. 2018.3197

14 Mallis P, Kostakis A, Stavropoulos-Giokas C and Michalopoulos E: Future perspectives in small-diameter vascular graft engineering. Bioengineering (Basel) 7(4): 160, 2020. PMID: 33321830. DOI: 10.3390/bioengineering7040160

15 Obiweluozor FO, Emechebe GA, Kim DW, Cho HJ, Park CH, Kim CS and Jeong IS: Considerations in the development of small-diameter vascular graft as an alternative for bypass and reconstructive surgeries: a review. Cardiovasc Eng Technol 11(5): 495-521, 2020. PMID: 32812139. DOI: 10.1007/s13239020-00482-y

16 Goh ET, Wong E, Farhatnia Y, Tan A and Seifalian AM: Accelerating in situ endothelialisation of cardiovascular bypass grafts. Int J Mol Sci 16(1): 597-627, 2014. PMID: 25551605. DOI: $10.3390 /$ ijms 16010597 
17 Wulff B, Stahlhoff S, Vonthein R, Schmidt A, Sigler M, Torsello GB and Herten M: Biomimetic heparan sulfate-like coated ePTFE grafts reduce in-graft neointimal hyperplasia in ovine carotids. Ann Vasc Surg 40: 274-284, 2017. PMID: 28163179. DOI: $10.1016 /$ j.avsg.2016.09.015

18 Wang Z, Mithieux SM and Weiss AS: Fabrication techniques for vascular and vascularized tissue engineering. Adv Healthc Mater 8(19): e1900742, 2019. PMID: 31402593. DOI: 10.1002/ adhm.201900742

19 Copes F, Chevallier P, Loy C, Pezzoli D, Boccafoschi F and Mantovani D: Heparin-modified collagen gels for controlled release of pleiotrophin: potential for vascular applications. Front Bioeng Biotechnol 7: 74, 2019. PMID: 31024906. DOI: 10.3389/fbioe. 2019.00074

20 Samson RH, Morales R, Showalter DP, Lepore MR Jr and Nair DG: Heparin-bonded expanded polytetrafluoroethylene femoropopliteal bypass grafts outperform expanded polytetrafluoroethylene grafts without heparin in a long-term comparison. J Vasc Surg 64(3): 638-647, 2016. PMID: 27139782. DOI: $10.1016 /$ j.jvs.2016.03.414

21 Matsuzaki Y, Wiet MG, Boe BA and Shinoka T: The real need for regenerative medicine in the future of congenital heart disease treatment. Biomedicines 9(5): 478, 2021. PMID 33925558. DOI: 10.3390/biomedicines 9050478

22 Durko AP, Yacoub MH and Kluin J: Tissue engineered materials in cardiovascular surgery: the surgeon's perspective. Front Cardiovasc Med 7: 55, 2020. PMID: 32351975. DOI: 10.3389/ fcvm.2020.00055

23 Jeong Y, Yao Y and Yim EKF: Current understanding of intimal hyperplasia and effect of compliance in synthetic small diameter vascular grafts. Biomater Sci 8(16): 4383-4395, 2020. PMID: 32643723. DOI: 10.1039/d0bm00226g

24 Post A, Diaz-Rodriguez P, Balouch B, Paulsen S, Wu S, Miller J, Hahn M and Cosgriff-Hernandez E: Elucidating the role of graft compliance mismatch on intimal hyperplasia using an $e x$ vivo organ culture model. Acta Biomater 89: 84-94, 2019. PMID: 30878448. DOI: 10.1016/j.actbio.2019.03.025

25 Neufang A: Xenogene materialien. In: Operative und interventionelle gefäßmedizin. Debus ES, Gross-Fengels W (eds.). Berlin, Heidelberg, Springer Berlin Heidelberg, pp. 287 293, 2020.

26 Bai H, Wang Z, Li M, Sun P, Wang W, Liu W, Wei S, Wang Z, Xing $\mathrm{Y}$ and Dardik A: A rat arteriovenous graft model using decellularized vein. Vascular 28(5): 664-672, 2020. PMID: 32390561. DOI: 10.1177/1708538120923191

27 Kostakis ID and Loukopoulos I: Comparison between bovine carotid artery graft and polytetrafluoroethylene graft for haemodialysis vascular access: A systematic review and metaanalysis. J Vasc Access 22(1): 26-33, 2021. PMID: 32495711. DOI: $10.1177 / 1129729820926088$

28 Burghuber CK, Konzett S, Eilenberg W, Nanobachvili J, Funovics MA, Hofmann WJ, Neumayer C and Domenig CM: Novel prefabricated bovine pericardial grafts as alternate conduit for septic aortoiliac reconstruction. J Vasc Surg 73(6): 2123 2131.e2, 2021. PMID: 33278536. DOI: 10.1016/j.jvs. 2020.11.028

29 Guler S, Aydin HM, Lü LX and Yang Y: Improvement of decellularization efficiency of porcine aorta using dimethyl sulfoxide as a penetration enhancer. Artif Organs 42(2): 219-230, 2018. PMID: 28913873. DOI: 10.1111/aor.12978
30 Lin $\mathrm{CH}$, Hsia $\mathrm{K}$, Ma H, Lee $\mathrm{H}$ and Lu JH: In vivo performance of decellularized vascular grafts: a review article. Int J Mol Sci 19(7): 2101, 2018. PMID: 30029536. DOI: 10.3390/ ijms 19072101

31 Eyre K, Samper E, Haverich A, Hilfiker A and Andrée B: Reendothelialization of non-detergent decellularized porcine vessels. Artif Organs 45(4): E53-E64, 2021. PMID: 33001470. DOI: $10.1111 /$ aor.13836

32 He Z, Liu G, Ma X, Yang D, Li Q and Li N: Comparison of small-diameter decellularized scaffolds from the aorta and carotid artery of pigs. Int J Artif Organs 44(5): 350-360, 2021. PMID: 32988264. DOI: 10.1177/0391398820959350

33 Jung O, Radenkovic M, Stojanović S, Lindner C, Batinic M, Görke O, Pissarek J, Pröhl A, Najman S and Barbeck M: In vitro and in vivo biocompatibility analysis of a new transparent collagen-based wound membrane for tissue regeneration in different clinical indications. In Vivo 34(5): 2287-2295, 2020. PMID: 32871752 . DOI: $10.21873 /$ invivo. 12040

34 Jung O, Smeets R, Hartjen P, Schnettler R, Feyerabend F, Klein $\mathrm{M}$, Wegner $\mathrm{N}$, Walther $\mathrm{F}$, Stangier $\mathrm{D}$, Henningsen A, Rendenbach C, Heiland M, Barbeck M and Kopp A: Improved in vitro test procedure for full assessment of the cytocompatibility of degradable magnesium based on ISO 10993-5/-12. Int J Mol Sci 20(2): 255, 2019. PMID: 30634646. DOI: $10.3390 /$ ijms 20020255

35 Steigmann L, Jung O, Kieferle W, Stojanovic S, Proehl A, Görke O, Emmert S, Najman S, Barbeck $M$ and Rothamel D: Biocompatibility and immune response of a newly developed volume-stable magnesium-based barrier membrane in combination with a PVD coating for guided bone regeneration (GBR). Biomedicines 8(12): 636, 2020. PMID: 33419327. DOI: 10.3390/biomedicines 8120636

36 Jung O, Smeets R, Porchetta D, Kopp A, Ptock C, Müller U, Heiland M, Schwade M, Behr B, Kröger N, Kluwe L, Hanken $\mathrm{H}$ and Hartjen P: Optimized in vitro procedure for assessing the cytocompatibility of magnesium-based biomaterials. Acta Biomater 23: 354-363, 2015. PMID: 26073090. DOI: 10.1016/ j.actbio.2015.06.005

37 Gratzer PF, Harrison RD and Woods T: Matrix alteration and not residual sodium dodecyl sulfate cytotoxicity affects the cellular repopulation of a decellularized matrix. Tissue Eng 12(10): 2975-2983, 2006. PMID: 17518665. DOI: 10.1089/ten. 2006.12.2975

38 Liu X, Cai Y, Xia C, Wu H, Li Q, Xu Z and Lu F: An innovative method to obtain porous porcine aorta scaffolds for tissue engineering. Artif Organs 43(12): 1162-1169, 2019. PMID: 31211855. DOI: 10.1111 /aor.13519

$39 \mathrm{Wu}$ P, Kimura T, Tadokoro H, Nam K, Fujisato T and Kishida A: Relation between the tissue structure and protein permeability of decellularized porcine aorta. Mater Sci Eng C Mater Biol Appl 43: 465-471, 2014. PMID: 25175237. DOI: 10.1016/ j.msec.2014.06.041

40 Zou Y and Zhang Y: Mechanical evaluation of decellularized porcine thoracic aorta. J Surg Res 175(2): 359-368, 2012. PMID: 21571306. DOI: $10.1016 /$ j.jss.2011.03.070

41 Stöwe I, Pissarek J, Moosmann P, Pröhl A, Pantermehl S, Bielenstein J, Radenkovic M, Jung O, Najman S, Alkildani S and Barbeck M: Ex vivo and in vivo analysis of a novel porcine aortic patch for vascular reconstruction. Int J Mol Sci 22(14): 7623, 2021. PMID: 34299243. DOI: 10.3390/ijms 22147623 
42 Blaudez F, Ivanovski S, Hamlet S and Vaquette C: An overview of decellularisation techniques of native tissues and tissue engineered products for bone, ligament and tendon regeneration. Methods 171: 28-40, 2020. PMID: 31394166 . DOI: 10.1016/ j.ymeth.2019.08.002

43 Gilpin A and Yang Y: Decellularization strategies for regenerative medicine: from processing techniques to applications. Biomed Res Int 2017: 9831534, 2017. PMID: 28540307. DOI: $10.1155 / 2017 / 9831534$

44 Badylak SF, Freytes DO and Gilbert TW: Reprint of: Extracellular matrix as a biological scaffold material: Structure and function. Acta Biomater 23 Suppl: S17-S26, 2015. PMID: 26235342. DOI: 10.1016/j.actbio.2015.07.016

45 García-Gareta E, Abduldaiem Y, Sawadkar P, Kyriakidis C, Lali $\mathrm{F}$ and Greco KV: Decellularised scaffolds: just a framework? Current knowledge and future directions. J Tissue Eng 11: 2041731420942903, 2020. PMID: 32742632. DOI: 10.1177/ 2041731420942903

$46 \mathrm{Li} \mathrm{N}$, Li Y, Gong D, Xia C, Liu X and Xu Z: Efficient decellularization for bovine pericardium with extracellular matrix preservation and good biocompatibility. Interact Cardiovasc Thorac Surg 26(5): 768-776, 2018. PMID: 29340634. DOI: $10.1093 /$ icvts/ivx416

47 Behl JD, Verma NK, Tyagi N, Mishra P, Behl R and Joshi BK: The major histocompatibility complex in bovines: a review. ISRN Vet Sci 2012: 872710, 2012. PMID: 23738132. DOI: $10.5402 / 2012 / 872710$

48 Aldridge A, Desai A, Owston H, Jennings LM, Fisher J, Rooney P, Kearney JN, Ingham E and Wilshaw SP: Development and characterisation of a large diameter decellularised vascular allograft. Cell Tissue Bank 19(3): 287-300, 2018. PMID: 29188402. DOI: 10.1007/s10561-017-9673-y

49 Kobayashi M, Ohara M, Hashimoto Y, Nakamura N, Fujisato T, Kimura $\mathrm{T}$ and Kishida $\mathrm{A}$ : In vitro evaluation of surface biological properties of decellularized aorta for cardiovascular use. J Mater Chem B 8(48): 10977-10989, 2020. PMID: 33174886. DOI: $10.1039 / \mathrm{d} 0$ tb01830a

50 Liu X, Cai Y, Xia C, Wu H, Li Q, Xu Z and Lu F: An innovative method to obtain porous porcine aorta scaffolds for tissue engineering. Artif Organs 43(12): 1162-1169, 2019. PMID: 31211855. DOI: $10.1111 /$ aor.13519

51 Anibueze C, Sankaran V, Sadat U, Tan K, Wilson YG, Brightwell RE, Delbridge MS and Stather PW: Neoaortic xenoprosthetic grafts for treatment of mycotic aneurysms and infected aortic grafts. Ann Vasc Surg 44: 419.e1-419.e12, 2017. PMID: 28642109. DOI: 10.1016/j.avsg.2017.02.021

52 Olde Damink L, Dijkstra P, Van Luyn M, Van Wachem P, Nieuwenhuis $\mathrm{P}$ and Feijen J: Glutaraldehyde as a crosslinking agent for collagen-based biomaterials. Journal of Materials Science: Materials in Medicine 6(8): 460-472, 2019. DOI: $10.1007 /$ bf00123371

53 Casali DM, Yost MJ and Matthews MA: Eliminating glutaraldehyde from crosslinked collagen films using supercritical $\mathrm{CO}_{2}$. J Biomed Mater Res A 106(1): 86-94, 2018. PMID: 28869704. DOI: 10.1002/jbm.a.36209

54 Gao S, Yuan Z, Guo W, Chen M, Liu S, Xi T and Guo Q: Comparison of glutaraldehyde and carbodiimides to crosslink tissue engineering scaffolds fabricated by decellularized porcine menisci. Mater Sci Eng C Mater Biol Appl 71: 891-900, 2017. PMID: 27987786. DOI: 10.1016/j.msec.2016.10.074
55 Jiang Q, Reddy N, Zhang S, Roscioli N and Yang Y: Waterstable electrospun collagen fibers from a non-toxic solvent and crosslinking system. J Biomed Mater Res A 101(5): 1237-1247, 2013. PMID: 23008183. DOI: 10.1002/jbm.a.34422

56 Marinucci L, Lilli C, Guerra M, Belcastro S, Becchetti E, Stabellini G, Calvi EM and Locci P: Biocompatibility of collagen membranes crosslinked with glutaraldehyde or diphenylphosphoryl azide: an in vitro study. J Biomed Mater Res A 67(2): 504-509, 2003. PMID: 14566791. DOI: 10.1002/jbm.a.10082

57 Speer DP, Chvapil M, Eskelson CD and Ulreich J: Biological effects of residual glutaraldehyde in glutaraldehyde-tanned collagen biomaterials. J Biomed Mater Res 14(6): 753-764, 1980. PMID: 6820019. DOI: 10.1002/jbm.820140607

58 Yang Y, Ritchie AC and Everitt NM: Comparison of glutaraldehyde and procyanidin cross-linked scaffolds for soft tissue engineering. Mater Sci Eng C Mater Biol Appl 80: 263273, 2017. PMID: 28866164. DOI: 10.1016/j.msec.2017.05.141

59 Jana S: Endothelialization of cardiovascular devices. Acta Biomater 99: 53-71, 2019. PMID: 31454565. DOI: 10.1016/ j.actbio.2019.08.042

60 Iop L, Palmosi T, Dal Sasso E and Gerosa G: Bioengineered tissue solutions for repair, correction and reconstruction in cardiovascular surgery. J Thorac Dis 10(Suppl 20): S2390S2411, 2018. PMID: 30123578. DOI: 10.21037/jtd.2018.04.27

61 Seifalian AM, Tiwari A, Hamilton G and Salacinski HJ: Improving the clinical patency of prosthetic vascular and coronary bypass grafts: the role of seeding and tissue engineering. Artif Organs 26(4): 307-320, 2002. PMID: 11952502. DOI: $10.1046 / j .1525-1594.2002 .06841 . x$

62 Chong DS, Lindsey B, Dalby MJ, Gadegaard N, Seifalian AM and Hamilton G: Luminal surface engineering, 'micro and nanopatterning': potential for self endothelialising vascular grafts? Eur J Vasc Endovasc Surg 47(5): 566-576, 2014. PMID: 24642295. DOI: $10.1016 /$ j.ejvs.2014.02.007

63 Zhuang Y, Zhang C, Cheng M, Huang J, Liu Q, Yuan G, Lin K and $\mathrm{Yu} \mathrm{H}$ : Challenges and strategies for in situ endothelialization and long-term lumen patency of vascular grafts. Bioact Mater 6(6): 1791-1809, 2020. PMID: 33336112. DOI: 10.1016/ j.bioactmat.2020.11.028

64 Shojaee $\mathrm{M}$ and Bashur CA: Compositions including synthetic and natural blends for integration and structural integrity: engineered for different vascular graft applications. Adv Healthc Mater 6(12), 2017. PMID: 28371505. DOI: 10.1002/adhm. 201700001

65 Sánchez PF, Brey EM and Briceño JC: Endothelialization mechanisms in vascular grafts. J Tissue Eng Regen Med 12(11): 2164-2178, 2018. PMID: 30079631. DOI: 10.1002/term.2747

66 Ricard-Blum S: The collagen family. Cold Spring Harb Perspect Biol 3(1): a004978, 2011. PMID: 21421911. DOI: 10.1101/ cshperspect.a004978

67 Cocciolone AJ, Hawes JZ, Staiculescu MC, Johnson EO, Murshed $\mathrm{M}$ and Wagenseil JE: Elastin, arterial mechanics, and cardiovascular disease. Am J Physiol Heart Circ Physiol 315(2): H189-H205, 2018. PMID: 29631368. DOI: 10.1152/ajpheart. 00087.2018

68 Mithieux SM and Weiss AS: Elastin. Adv Protein Chem 70: 437-461, 2005. PMID: 15837523. DOI: 10.1016/S0065-3233(05)70013-9

69 van Tienen TG, Hannink G and Buma P: Meniscus replacement using synthetic materials. Clin Sports Med 28(1): 143-156, 2009. PMID: 19064171. DOI: 10.1016/j.csm.2008.08.003 
70 Datta P, Ayan B and Ozbolat IT: Bioprinting for vascular and vascularized tissue biofabrication. Acta Biomater 51: 1-20, 2017. PMID: 28087487. DOI: 10.1016/j.actbio.2017.01.035

71 Ren X, Feng Y, Guo J, Wang H, Li Q, Yang J, Hao X, Lv J, Ma $\mathrm{N}$ and $\mathrm{Li} \mathrm{W}$ : Surface modification and endothelialization of biomaterials as potential scaffolds for vascular tissue engineering applications. Chem Soc Rev 44(15): 5680-5742, 2015. PMID: 26023741. DOI: $10.1039 / \mathrm{c} 4 \mathrm{cs} 00483 \mathrm{c}$

72 Aslani S, Kabiri M, HosseinZadeh S, Hanaee-Ahvaz H, Taherzadeh ES and Soleimani M: The applications of heparin in vascular tissue engineering. Microvasc Res 131: 104027, 2020. PMID: 32505610. DOI: 10.1016/j.mvr.2020.104027
73 Goins A, Webb AR and Allen JB: Multi-layer approaches to scaffold-based small diameter vessel engineering: A review. Mater Sci Eng C Mater Biol Appl 97: 896-912, 2019. PMID: 30678980. DOI: $10.1016 /$ j.msec.2018.12.067

74 Huang $\mathrm{AH}$ and Niklason LE: Engineering of arteries in vitro. Cell Mol Life Sci 71(11): 2103-2118, 2014. PMID: 24399290. DOI: $10.1007 / \mathrm{s} 00018-013-1546-3$

Received October 9, 2021

Revised October 22, 2021

Accepted October 26, 2021 